\title{
Materiality vs. Expressivity: The Use of Sensory Vocabulary in Yucatec Maya
}

\section{Olivier Le Guen}

Olivier Le Guen is an ethnographer working among the Yucatec Maya. His research lies in the field of linguistic anthropology and explores the way culture and language influence human cognition in the realm of social interaction. ompleguen@gmail.com
ABSTRACT In this article, sensory vocabulary relating to color, texture, and other sensory experiences in Yucatec Maya (a language spoken in Mexico) is examined, and its possible relation to material culture practices explored. In Yucatec Maya, some perceptual experience can be expressed in a fine-grained way through a compact one-word adjective. Complex notions can be succinctly expressed by combining roots with a general meaning and applying templates or compounds to those sensory roots. For instance, the root tak', which means 'adhere/adherence,' can be derived to express the notion of 'dirty red' chak-tak'-e'en or 'sticky with an unbounded pattern' tak'aknak, or the root ts'ap 'piled-up' can express 'several 
tones of green (e.g. in the forest)' ya'axts'ape'en or 'piled-up, known through a tactile experience' ts'aplemak. The productive nature of this linguistic system seems at first glance to be very well fitted to orient practices relating to the production of local material culture. In examining several hours of video-recorded natural data contrasting work and non-work directed interactions, it emerges that sensory vocabulary is not used for calibrating knowledge but is instead recruited by speakers to achieve vividness in an effort to verbally reproduce the way speakers experience percepts.

KEYWORDS: color, language of perception, material culture, Yucatec Maya, Mexico

\section{Introduction}

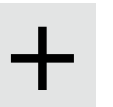

Can color and texture vocabulary (here referred to as "sensory vocabulary") be taken to be a direct result of the material culture or degree of technological development that exists in a given community? In some cases, there appears to be a causal relation between material culture and the production of vocabulary. Take for instance the French ironworks lexicon. A word like moraillon refers to a specific artifact, namely a flat metal piece hinged on the frame of a door or on a chest, where the lock bolt runs through. The existence of the word moraillon is a direct consequence of the invention of door and chest closure technology; if this technology disappeared, this word would likely fall out of use.

In the discussion regarding the interaction between the senses and language, authors have argued that basic color terms are synchronically or diachronically related to the expansion of material culture and technologies such as painting or dyeing clothing (Berlin and Kay 1969; Levinson 2000). Such a hypothesis implies that sensory words (here, the color lexicon) are directly related to the materiality of the speakers' environment, the way moraillon is to ironworks in French.

In this article, a subset of Yucatec Maya sensory vocabulary relating to color, texture, and other sensory experiences is examined, in order to explore its possible relation to material culture practices. First, this article offers a short description of the language and speech community setting. Then, specific linguistic strategies to form sensory words are examined. The last part of the article examines occurrences of sensory words and their use in videotaped natural interactions. It is argued that even if sensory words can appear as closely bounded to material culture, they are in fact used to convey expressivity. 


\section{Yucatec Maya and Its Speakers}

Yucatec Maya is a language spoken in the Yucatán peninsula in Mexico and in Northern Belize, with the number of speakers approximating 759000 in 2005 (INEGI 2005). The work reported here is based on fieldwork in two Yucatec Maya communities. Linguistic data presented in this article were collected in the Mayan language using standard ethnographical observation together with elicitation and experimental procedures.

\section{The Construction of Sensory Words in Yucatec Maya}

Yucatec Maya starts not with individual lexical items (like nouns) but rather with roots that provide semantic and morphologic "raw material." Yucatec Maya has a core set of consonant-vowelconsonant (CVC) roots, and relies on productive derivational processes to form stems (Lois and Vapnarsky 2006). The derivational process transforms roots into particular classes of words (here only adjectives are considered) and also adds some semantic information to the final word. The root when derived or compounded gains more specific meaning that relates to sensory experience or spatial distribution. For instance, the root tak' has a basic meaning of 'adhere, adherence' and it can be derived to tatak'kil 'sticky,' tak'lemak 'sticky (perceived through touch),' tak'atak' 'several items stuck with small in-between space' or tak'éentáak' 'several items stuck with large in-between space.' In a compound with the word 'red,' as in chaktak'e'en, it suggests a type of 'dirty red.' The next section describes the derivational process in more detail. Then a second strategy for producing sensory vocabulary is presented, where two different roots are compounded. These different linguistic processes enable Yucatec speakers to express complex perceptual gestalts.

\section{The Formation of Expressive Words with Derivation Templates}

To construct sensory adjectives, several templates are available, each of which provides a specific meaning when applied to a root meaning.

The CV-CVC-kil template Probably the most common template to create sensory words is CV-CVC-kil that transforms a root into an adjective by taking the root and applying a partial reduplication of it and then adding the suffix -kil. The meaning provided by this template is quite broad. It refers to the general property of an object, and suggests above all something about its visual experience (see the examples in Table 1).

The CVC-lemak and CVC-vknak template The CVC-lemak and CVC-vknak templates also transform roots into adjectives. However, 
Table 1 Derivation with CV-CV-kil.

\begin{tabular}{lllll}
\hline Root & English gloss & Adjective & English gloss & Examples of use \\
\hline 'op' 'break' & 'o'op'kil & $\begin{array}{c}\text { 'easily broken into pieces, } \\
\text { fragile' }\end{array}$ & dry tortilla, eggshell \\
k'ix & 'thorn' & k'ik'ixkil & 'stinging' & $\begin{array}{l}\text { rough or jagged fabric, three- } \\
\text { day growth of beard }\end{array}$ \\
lem 'bright visual event' & lelenkil & 'shiny' & $\begin{array}{l}\text { sparkling cloth, thunder, shiny } \\
\text { metal }\end{array}$ \\
\hline
\end{tabular}

in contrast to the CV-CVC-kil template, these templates imply a tactile experience rather than a visual one. The CVC-vknak template also denotes an idea of an unbounded pattern (like an extended surface but also a spherical surface). Consider the different meaning obtained when these templates are applied to the same roots previously used (see Table 2).

Since these two templates imply tactile or bodily perception, roots referring to a visual impression, such as lem, are semantically incompatible with these templates. Thus *lemlemak and *lemeknak (shiny through tactile experience) are not accepted as possible expressions by speakers.

The CVC-v(I)-CVC and the CVC-en/un-CV́vC templates In contrast with the previous templates, the CVC-V(I)-CVC and CVC-en/unCv́vC templates do not carry specific experience information. Instead these templates provide information about the way several entities are distributed in space. The difference between the two is in specifying the degree of separation between entities: CVC-V(I)-CVC

Table 2 Derivation with CVC-lemak and CVC-vknak.

\begin{tabular}{lll}
\hline Adjective & \multicolumn{1}{c}{ English gloss } & \multicolumn{1}{c}{ Examples of use } \\
\hline 'op'lemak & $\begin{array}{l}\text { 'easily broken (tactile/body } \\
\text { experience)' }\end{array}$ & dried tortilla crushed by hand \\
'op'oknak & $\begin{array}{l}\text { 'easily broken (tactile/ } \\
\text { body experience with } \\
\text { unbounded pattern)' }\end{array}$ & light bulb crushed with the fingers \\
k'ixlemak & $\begin{array}{l}\text { 'stinging (tactile/body } \\
\text { experience)' }\end{array}$ & $\begin{array}{l}\text { having a small piece of wood in } \\
\text { the eye }\end{array}$ \\
k'ixinak & $\begin{array}{l}\text { 'stinging (tactile/ } \\
\text { body experience with } \\
\text { unbounded pattern)' }\end{array}$ & rubbing the fur of a wild boar \\
\hline
\end{tabular}


implies a small in-between space while CVC-en/un-Cv́vC implies a large in-between space of entities.

To illustrate, k'ix becomes k'ixik'ix (e.g. several thorns on the bark of a tree close to one another) and k'ixunk'iix (e.g. several groups of thorns spread over on the bark of a tree). Examples of the root lem with these templates are more difficult to find but are possible, for example lemunléem (e.g. several soldiers with shiny swords to their belts).

The sensory grid and the template What is striking in the formation of sensory words in Yucatec Maya is the availability of a sort of "ready-to-perceive" grid of interpretation of the world provided by these templates. Seven Yucatec Maya participants from Kopchen (four women and three men aged between thirty and forty-six) were shown a photograph of a road full of potholes and asked to describe it. ${ }^{1}$ In order to render the idea that the road is full of potholes, Yucatec Maya participants agreed on the use the of the root k'om 'hollow,' but they differed in which template they used and thus conveyed different understandings or aspects of the same object. The core meaning of k'om refers broadly to the idea of 'hollowness' but, once derived according to a template, kom specifies a possible realization of the concept of hollowness. Consider examples 1 to 4 , responses from the participants:

1. k'om-o-k'om le beho' - 'the road has many holes distributed with small spaces in-between'

2. k'om-en-k'óom le beho' - 'the road has many holes distributed with large spaces in-between'

3. k'om-lemak le beho' - 'the road is bumpy (= hollowness is felt physically, e.g. as one drives on the road)'

4. k'om-oknak le beho' - 'the road is bumpy (as in k'omlemak), not only this portion but the entire road'

\section{The Formation of Words as Sensory Compounds}

In contrast with the derivational process described above, Yucatec speakers can also use compounds to express specific percepts. In a compound, meaning is composed by the combining of two roots.

In Yucatec Maya, as in other Mayan languages (see Haviland n.d.; Bricker 1999; Brown, this issue) there is a specific type of compound that combines an initial sensory root $\left(\mathrm{CVC}^{1}\right)$, with a second root taken from a non-sensory domain $\left(\mathrm{CVC}^{2}\right)$ and ends with a final particle (the suffix -e'en). CVC' consists of a small class (the five basic Maya color terms, the terms for 'lukewarm' k'iin and 'cold,' siis and some less frequent terms such as 'clear' sáas or 'flat, clear' han), while CVC² can be almost any verbo-nominal root. Bricker (1999) considers this compound as a special class of affects that focuses on color and texture but can also extend to other sensory experiences, such as temperature. 
Table 3 Derivation in compound with 'red.'

\begin{tabular}{|c|c|c|c|c|}
\hline (7) & $C V C^{1}$ & $C V C^{2}$ & Suffix & $\begin{array}{c}\text { Output term and English } \\
\text { gloss }\end{array}$ \\
\hline (a) & & $\begin{array}{l}\text {-hul- } \\
\text { 'beam' }\end{array}$ & & $\begin{array}{l}\text { chak-hul-e'en } \\
\text { 'red-beaming' }\end{array}$ \\
\hline (b) & & $\begin{array}{l}\text {-t'ab- } \\
\text { 'light up' }\end{array}$ & & $\begin{array}{l}\text { chak-t'ab-e'en } \\
\text { 'red-lighting up' }\end{array}$ \\
\hline (c) & $\begin{array}{l}\text { chak- } \\
\text { 'red' }\end{array}$ & $\begin{array}{l}\text {-hop'- } \\
\text { 'start' }\end{array}$ & -e'en & $\begin{array}{l}\text { chak-hop-e'en } \\
\text { 'red-starting to fire up' }\end{array}$ \\
\hline (d) & & $\begin{array}{l}\text {-hup- } \\
\text { 'dry out' }\end{array}$ & & $\begin{array}{l}\text { chak-hup-e'en } \\
\text { 'red-drying/fading out' }\end{array}$ \\
\hline (e) & & $\begin{array}{l}\text {-nik- } \\
\text { 'spread out, fallen } \\
\text { without order' }\end{array}$ & & $\begin{array}{l}\text { chak-nik-e'en } \\
\text { 'red-spread out' }\end{array}$ \\
\hline
\end{tabular}

As an example of the productive character of sensory compounds consider the descriptions provided by the same seven Yucatec Maya participants of a photo of a hearth with embers. Their descriptions are schematized in examples 5(a-e) (see Table 3).

The informants' responses are all compounds built from the root chak 'red.' All the descriptions are felicitous, but each specifies a different way in which the embers are red, revealing different interpretations of the same event. Participants differed in their construal of how to interpret the current state of the fireplace. Some informants considered that the fire was about to start up again $(5 a-c)$, whereas others saw it as dying down $(5 d)$, and others were more concerned with the spatial distribution of the embers as in (5e).

Sensory compounds can also apply to temperature terms; the same scene of a hearth with embers could as well have been described as k'iin-t'ab-e'en, 'firing up,' using the roots k'iin 'lukewarm' and t'ab 'light up' (identical to 5b) with a focus on the thermal sensation rather than the color.

\section{The Corpus Study}

Sensory words in Yucatec Maya would appear to be good candidates for talking about material culture. One can readily imagine these words being used to guide the process of artifact fabrication (especially artifacts that imply some pattern, like basket weaving) (Dingemanse, this issue). To test this hypothesis, a corpus study was conducted looking at when and how these sensory words are used in naturally occurring interactions and narrations. All sessions were recorded in two Yucatec Maya villages (Chemax and Kopchen). The interactions are divided in two types: sessions where people were engaged 
in a work activity vs. sessions where people where just having an informal conversation. In total, the data analyzed represents 5 hours of transcribed interactions divided into works sessions (147.38 minutes with 848 utterances) and session of ordinary conversation (152 minutes with 4,555 utterances).

\section{Analysis of the Data}

In the data examined, the fifteen sensory words collected appear almost equally in work and conversation sessions. However, they almost exclusively are used in informal conversations and in experience-based narratives. Analysis shows only two examples of sensory words occurring during ongoing work activities. In one occurrence, a woman who is getting a medicinal massage uses the word sasap'kil 'dried up' (sap' 'dry up' + CV-CVC-kil) to talk about her dry nose and mouth, symptoms of her illness.

Overall, the majority of the examples found in the corpus were used to convey vividness and crossmodal information, as in example 6 . This is an extract from one hour of a recorded work session where four men are involved in digging a pit oven, placing stones, and manipulating tools. The sensory words found in this session are not about the ongoing activity. Among the seven sensory word types used in the session, five appear while the men are discussing the feature of a particular type of rifle.

(6) J: máa yàan ts'òon úuchbene' mehen ch'amach'am tinwilah NEG.INTR EXIST rifle old.TD small dent-v-CVC AM.1ERG. see.TR.CP

pero elo' ma' chen awach'e' ùutsi fyèero yani' but these NEG only good.NOM iron EXIST.TD 2.ERGopen.TD

"Aren't there some old rifles (like the one) I saw with little dented patterns [with small in-between spaces], but those, as you open them (you see that) the iron is fine"

E: lenlenkil lenlenkil toabya tak ubarnisil ufyerosilo' CV.shine.kil CV.shine.kil still even 3.ERG.varnish.NOM 3.ERG.iron.NOM.TD

"It's shiny, it's still shiny, even the varnish of the iron"

F: ya'axleme'en green.shine.SUFF "It is green-shiny"

J: tu'ux kawilik ch'amlemak where AM.2.ERG.see/apreciate.TR dent-lemak "Where you can appreciate it is dented [tactile experience]" [2009-06-12_1854-natconv_menpaanpiib-1536-15'49] 
To describe the rifle, the first speaker $(\mathrm{J})$ tries to convey the particular dented aspect of the rifle using the root ch'am 'dent,' deriving it according to two templates. First, he refers to the dense spatial arrangement of the dents recruiting the CVC-V-CVC template in ch'amach'am 'dent + several entities distributed with small inbetween space.' After others have commented on the visual aspect of the rifle, $\mathrm{J}$ takes the floor again to continue his description. This time, he puts emphasis on the tactile aspect of the dented rifle in recruiting the CVC-lemak template in ch'amlemak 'dent + tactile experience.' The stress on the tactile experience is promoted by the gesture $\mathrm{J}$ produces with his utterance as he touches the bark of the tree next to him.

In his utterances, $\mathrm{J}$ focuses on the texture of the rifle, using spatial distribution and tactile experience templates. In contrast, other speakers are apparently more concerned with the visual aspects of the rifle. E points out that the wood and the varnish of this particular type of rifle is lenlenkil 'shiny.' F goes one step further and, building on the same root lem 'shiny,' specifies it is actually ya'axleme'en 'green-shiny.'

In this exchange, sensory words do not contribute to organize the activity, for instance to talk about spatial distribution of the stones, nor do they refer to the aspect of the earth being dug, etc. Instead, sensory words are recruited by the speakers to evoke an object that is absent in the scene, the rifle. Instead of talking about the form or the function of the rifle, speakers in the extract focus on the visual appearance and tactile aspect of the rifle in trying to reproduce it linguistically, using sensory words with crossmodal meaning. Such use of sensory vocabulary not only contributes to the accuracy of the description but also to the verification of speaker's understanding (Nuckolls 1995; Dingemanse, this issue)

\section{Discussion}

Although sensory words seem well fitted to be used as technical vocabulary to describe the materiality of the world, they are in fact recruited by speakers to achieve vividness. In the interactions analyzed, sensory words are used by speakers to verbally reproduce the way they experience percepts. This suggests that sensory language is driven more by aesthetic and expressive motivations than practical ones.

\section{Acknowledgments}

This study was carried out as part of the Language of Perception study within the Categories across Language and Cognition project at the Max Planck Institute for Psycholinguistics. Special thanks go to my informants and friends in the field for their willingness to share with me their knowledge and for their infinite patience. I am indebted to Lorena Pool Balam, Penelope Brown, Asifa Majid, and Elisabeth 
Norcliffe for their comments and help on this article. This research was funded by the Max Planck Gesellschaft.

\section{Notes}

1. Interested readers are welcome to contact the author if they wish to see a copy of the image.

\section{References}

Berlin, Brent and Kay, Paul. 1969. Basic Color Terms: Their Universality and Evolution. Berkeley, CA: University of California Press.

Bricker, Victoria R. 1999. "Color and Texture in the Maya Language of Yucatan." Anthropological Linguistics 41(3): 283-307.

Haviland, John B. n.d. "White-Blossomed on Bended Knee: Linguistic Mediation of Nature and Culture." In Roberto Zavala and Thomas Smith-Stark (eds), A Festschrift for Terry Kaufman. Forthcoming.

INEGl. 2005. Il Conteo de Población y Vivienda 2005. Mexico: INEGl. Levinson, Stephen C. 2000. "Yélî Dnye and the Theory of Basic Color Terms." Journal of Linguistic Anthropology 10(1): 3-55

Lois, Ximena and Vapnarsky, Valentina. 2006. Lexical Categories and Root Classes in Amerindian Languages. Bern: Peter Lang.

Nuckolls, Janis B. 1995. Sounds Like Life: Sound Symbolic Grammar, Performance, and Cognition. New York: Oxford University Press. 